\title{
Identifying the third agers: An analysis of British retirees' leisure pursuits
}

1. Stella Chatzitheochari, Department of Sociology, University of Surrey, Guildford

2. Sara Arber, Department of Sociology, University of Surrey, Guildford

Correspondence to: Stella Chatzitheochari, Department of Sociology, University of Surrey, Guildford, GU2 7XH or stella.chatzitheochari@surrey.ac.uk

Published in Sociological Research Online, 2011, 16(4) http://www.socresonline.org.uk/16/4/3.html

\begin{abstract}
Despite the recent theoretical focus on the emergence of the Third Age as a period of fulfilment and an ongoing engagement with an active leisure lifestyle, there is a dearth of quantitative studies on how older people spend their time. Few studies of later life capitalise on time-use surveys, which constitute the most widely employed and accurate methodology for collecting data on everyday life. This article analyses data from the 2000 UK Time Use Survey in order to operationalise the concept of the Third Age and test theoretical propositions regarding the irrelevance of social divisions in the formation of an active leisure lifestyle after retirement. The analysis focuses on a subsample of 1615 people over the age of 64 . An index of active leisure activities is constructed in order to estimate the proportion of third agers amongst British retirees. Logistic regression models are specified to examine the relative influence of socio-demographic characteristics on the probability of a person being a third ager. Strong effects of structural factors and health are found, which do not support arguments suggesting a minor influence of social context in lifestyle choices after retirement. 'Active' ageing appears to be the province of those who are culturally and materially advantaged, and it is the healthy, educated, upper-class and middle-class men that are more likely to engage in a Third Age leisure lifestyle.
\end{abstract}

\section{KEYWORDS}

Active Leisure; Retirement; Time-use Research; Third Age; Successful Ageing; UK 


\section{INTRODUCTION}

The everyday life of older people, particularly leisure, has always constituted a theme of central interest for sociologists of ageing (Kleemeier 1961; Howe 1987). Given that this lifecourse stage is characterized by an overall decrease in paid work and family commitments, and a corresponding increase in discretionary time and temporal autonomy, the basic questions of how older people spend their time and structure their everyday lives arise. Over the last three decades, Third Age theorists have viewed life after retirement as a time of selfactualization characterized by an expanded active leisure involvement, a development linked to the improved health status and economic resources of current cohorts of retirees in Western societies (Gilleard and Higgs 2000; Neugarten 1974; Laslett 1987). This 'new experience of ageing' was understood as an agentic and reflexive project that emerged irrespective of individuals' socio-economic circumstances and previous biographical experiences (Featherstone and Hepworth 1989), a conceptualization that moved away from life-course and political economy approaches that emphasized the importance of material disparities and social inequalities in creating different daily realities after retirement within a cohort (Phillipson 1998).

Despite the plethora of theoretical discussions about the Third Age and active ageing, empirical research on older people's leisure experiences has not advanced in a systematic manner (Wahl, Tesch-Romer and Hoff 2007). The majority of existing studies on the topic are qualitative, relying on small non-representative samples of older adults (for example see Bultena and Wood 1970; Hooker and Ventis 1984; Patterson 1996; Larson, Zuzanek and Mannell 1985; Wray 2003), while few analyses of large-scale representative data on postretirement activity patterns exist (Chung et al. 2009). Such analyses rely on conventional social surveys that utilize interviewer-administered questionnaires to gather information on participants' leisure engagement. However, this mode of data collection presents a series of methodological weaknesses, as it covers only a limited number of pre-specified leisure activities and provides inaccurate estimates of daily activity patterns (Robinson and Godbey 1997). It is surprising that few researchers have analysed time diary data to examine postretirement lifestyles (Gauthier and Smeeding 2001; 2003), although time-use surveys represent the most accurate and widely employed methodology for collecting data on time allocation, which rectifies the methodological weaknesses of conventional social survey data 
and produces a holistic picture of daily life (Michelson 2000; Robinson and Godbey 1997; Ver Ploeg 2000). By providing a complete account of human behaviour, diary data provide an opportunity to empirically examine the realization of Third Age lifestyles for current cohorts of retirees, and to investigate the relationship of active leisure engagement with structural disadvantage.

Taking into account the lack of quantitative studies on older people's activity patterns, this article capitalises on time-use data in order to operationalise the concept of Third Age leisure and estimate the proportions of British people over retirement age that could be characterized as third agers according to their engagement with active leisure pursuits. By examining the socio-economic characteristics of third agers, our study also assesses theoretical suggestions regarding the irrelevance of health and other structural constraints in the formation of a Third Age leisure lifestyle. The next section provides a brief overview of the theoretical concept of the Third Age.

\section{THE CONCEPT OF THE THIRD AGE}

Over recent decades, there has been a tendency among a substantial number of theorists of ageing to view life after retirement as an expanded leisure phase and a period of high activity and involvement (Gilleard and Higgs 2000; Neugarten 1974; Laslett 1987). While earlier approaches were built around the ideas of exclusion, dependency and disengagement of older people, who were depicted as needy and frail (Cummings and Henry 1966), recent theories have envisaged radical changes in the social category of older age and its experience. Despite some differences between these recent accounts, they all fall into the wider Third Age theoretical strand, which owes its origins to the work of Peter Laslett (1987).

In his seminal contribution, Laslett (1987) observed a series of demographic and sociological changes in contemporary Western societies and predicted the appearance of a new life-course stage, that of the Third Age. For Laslett, the emergence of retirement as a social institution, the higher living standards of retirees, the decrease in the retirement age and the increase of healthy years people were expected to enjoy after retirement laid the foundations for a different experience of mature age after the relinquishment of paid work and family roles. Combined with the increased opportunities for leisure participation and the more 'refined' needs and interests of newer generations as a result of different socialization experiences and resources, these changes would lead to an altered trajectory of individual 
ageing; the Third Age was thus conceptualized as a new life-course stage of extended and selffulfilling leisure and community participation following retirement. Its emergence was understood as a uniquely modern phenomenon that constituted a key development in the transformation of later life and of the entire life-course structure in Western societies (Gilleard and Higgs 2000; Weiss and Bass 2002).

The ideas of Laslett had many followers (Gilleard and Higgs 2000, 2005; Featherstone and Hepworth 1989; James and Wink 2007; Weiss and Bass 2002) and the concepts of the Third Age and active ageing soon became popular themes in the sociology of ageing. In addition to postulating a leisured post-retirement experience, a number of sociologists moved away from political economy approaches that had emphasized the importance of social inequalities in creating different daily realities after retirement within a cohort (Phillipson 1998). Ageing was viewed as an agentic reflexive project and active leisure was seen to emerge privately, independently of social divisions (Featherstone and Hepworth 1989). However, such claims have been contested by empirical research that underlines the persistence of cumulative social inequalities based on gender, ethnic and social class disadvantage associated with previous life-course stages that influence health status, pensions and retirement trajectories (for example see Arber and Evandrou 1993; Arber and Ginn 1995; Carr and Komp 2011; Dannefer; Matthews, Jagger, Hancock 2005). These disadvantages mean that the opportunities for engagement with Third Age lifestyles are unlikely to be distributed equally among older adults who may face new leisure constraints from caring responsibilities or reduced spending power after retirement. Additionally, inequalities experienced during previous life-course stages may foster different understandings of freedom, agency and selfrealization in later life (Wray 2003), which poses doubts as to whether agency in later life should only be understood as synonymous with activity participation. In parallel, a number of social gerontologists have suggested that the glorification of high activity in older ages by Third Age theorists is strongly determined by middle-class and male-centric Western bias (Bury 1995; Wray 2007) which is not sensitive to ethnic and other cultural differences in lifestyle preferences.

However, despite these critiques, discourses on the Third Age and active ageing have gradually acquired normative power on what was seen as 'good ageing' in Western societies. One reason for this has been the substantial number of empirical findings attesting a strong association between an active leisure lifestyle in retirement and positive subjective and objective health and quality of life (QoL) outcomes. Active leisure has been found to compress 
morbidity, increase individual well-being, reverse the rate of cognitive decline, promote reduction of social isolation among older people and increase overall life satisfaction (Sneegas 1986; Verghese et al. 2003; Riddick 1986). Additionally, leisure activities associated with the concept of the Third Age are also central to ideas regarding 'productive ageing' and older people's enhanced roles and contribution to the community (Bass and Caro 2001). As a result, active ageing has recently emerged as a political slogan and is being consistently promoted by public policies in the United Kingdom both at a national and at a local level (Department of Work Pensions 2005).

\section{RESEARCHING LEISURE IN THE THIRD AGE}

Leisure, which constitutes one of the main dimensions of the concept of the Third Age, has received relatively little attention in empirical research within social gerontology. Gauthier and Smeeding (2003) note that most studies on everyday life after retirement rely on small non-representative samples of respondents, often of less than 200 (for example see Hooker and Ventis 1984; Larson, Zuzanek and Mannell 1985; Wray 2003). Few analyses of large-scale representative datasets on daily life after retirement exist. Some researchers have explored the ageing process and assessed Third Age theories by examining consumption patterns of the retired population (Gilleard 1996; Gilleard et al. 2005). However, consumption cannot constitute a sufficient indicator of an active ageing lifestyle, as described by Third Age theories, since it is possible for retirees that purchase a high amount of material goods to actually have an exclusively passive and mostly 'indoor' lifestyle. For the study of the Third Age, it is more appropriate to conceptualize leisure as activity and differentiate between passive and active -either physical or cognitive- leisure pursuits.

Quantitative studies that have analysed activity patterns after retirement (Chung et al. 2009) have relied on data from leisure behaviour inventories that ask respondents how much time they spent on specific leisure activities during the previous day, week or month. There are a number of disadvantages in this methodological approach, particularly that it gathers information only on pre-specified activities and therefore fails to generate a full picture of everyday life. Another drawback is the reported inaccuracy of time estimates obtained due to the cognitive tasks the respondent has to undertake within a few seconds (Robinson and Godbey 1999).

Few studies have relied on time-use surveys to examine post-retirement lifestyles 
(Gauthier and Smeeding 2001; 2003), despite the fact that they currently represent the most widely employed methodology for collecting data on time allocation (Ver Ploeg 2000). What differentiates time-use surveys from other social surveys is the use of a self-completed diary for data collection, where respondents provide their own descriptions of activities across the full 24 hours of the day. Diaries gather information on the chronological structure and nature of daily activities, providing a holistic narrative account that is not obtained by conventional social surveys. A series of methodological studies have provided evidence on the advantages of time-use methodology in mitigating recall bias and social desirability concerning report of leisure activities, attesting an overall higher reliability of time-use data compared with data produced by other methodologies (Michaelson 2005; Robinson and Godbey 1999; Van der Ploeg et al 2010).

In this article we operationalise the concept of the Third Age with time-use data in order to estimate the proportions of older people that could be characterized as third agers in contemporary Britain according to their participation in active leisure activities. We then examine the relative contribution of socio-demographic characteristics on the probability of systematic engagement with an 'active' lifestyle after retirement age. To our knowledge, this is the first study that operationalises the concept of the Third Age with time-use data, as well as the first time-use analysis of retirees' leisure pursuits in contemporary Britain.

\section{METHODOLOGY}

\section{1) Data}

We analyse data from the 2000 UK Time Use Survey (thereafter UKTUS) - see 2000 TUS Technical Report (ONS 2003), which was conducted by the Office for National Statistics (ONS) between June 2000 and September 2001, and constitutes the most recent large-scale household time-use study that was conducted in the country. The time period surveyed by the UKTUS diary was 24 hours and all individuals over the age of 8 in sampled households were asked to fill in the diary for two pre-specified days: a weekday and a weekend day. Each diary consisted of 144 ten-minute slots and participants were asked to provide their own descriptions of their primary and secondary activities in each slot. Following the completion of fieldwork, respondents' descriptions were grouped into approximately 250 activity categories.

A total of 11,677 individuals completed 20,981 diaries and the UKTUS achieved a response rate of $62 \%$ and $72 \%$ at the household and diary level respectively, resulting in a net 
diary response rate of $45 \%$. Such rates are common in time-use surveys due to the heavy burden of diary completion posed to participants. However, a series of methodological studies have found that non-responders in time-use surveys cannot be identifiable by any major sociodemographic factor (Abraham et al. 2006; Kalfs 1993; Robinson \& Godbey 1999), lending support to the reliability of time-use data.

Our analysis is based on a subsample of 696 men and 919 women over 64 years old. This analytic sample consists primarily of retired individuals (95 per cent), and of only a small minority of older adults that remain economically active. Data are weighted in order to correct for non-response and make the sample representative of the UK population over the age of 64 . Activity duration estimates refer to the average time spent on each activity reported as primary over the two surveyed days.

\section{2) Operationalising the Third Age}

In this study the Third Age is understood as a time period of an ongoing engagement with an active leisure lifestyle after retirement age. Therefore we operationalise the concept by constructing an index of active leisure pursuits and consider weekly participation in these activities as an indicator of a Third Age lifestyle.

Approximately 250 diary activity categories were aggregated into 7 main activity categories: domestic work, personal care (including sleep), caring for children and/or other household members, socializing with others, passive indoor leisure, active/Third Age leisure and an 'other' category consisting of a few non-classifiable codes. Seven activity sub-categories were included in the active/Third Age leisure index: 1) engagement with arts, 2) entertainment, 3) physical exercise, 4) other outdoor hobbies in the countryside/nature, 5) voluntary work, 6) use of personal computers and the internet in general, and 7) recreational study. Table 1 provides details of the contents of each of the seven Third Age categories used to construct the active leisure index.

Six of these activity categories, namely arts, entertainment, recreational study, voluntary work, hobbies in nature/countryside and physical exercise can only take place out of the home, require advance planning, have a strong social component, and entail a more substantial mental and physical effort than indoor leisure pursuits. Computer use is the only activity within the Third Age/active leisure index that is, almost always, home-based. The decision to 
include computer use in the active/Third Age leisure index was made after consideration of the time period during which the fieldwork of the UKTUS took place: activities carry different meanings at different historical periods of time, and while it can be argued that computer use has now become more similar to passive mass media consumption such as watching television for many people, the assumption was made that a decade ago in 2000-2001 it was highly likely for the activity to be more cognitively demanding and engaging for the user ${ }^{1}$. Additionally, older peoples' computer use has been associated with the concept of the 'silver surfer' and lifelong learning (Seals et al. 2008; Shapira et al. 2007) and can thus be seen as signifying an engagement with the advances of modern society, a central element of the theoretical concept of the Third Age.

\begin{tabular}{ll} 
Category & Content \\
\hline Arts & $\begin{array}{l}\text { Doing visual arts (sculpture, photography), } \\
\text { performing and other literary arts }\end{array}$ \\
\hline Entertainment & $\begin{array}{l}\text { Going to the cinema, attending theatre plays, concerts, } \\
\text { musicals, exhibitions, sports events, hi storical sites, } \\
\text { botanical gardens, visiting museums }\end{array}$ \\
\hline Hobbies in Nature & Fishing, hunting, picking berries etc. \\
\hline Physical Exercise & $\begin{array}{l}\text { Jogging, biking, skiing, ball games, gymnastics, fitness, } \\
\text { water sports etc. }\end{array}$ \\
\hline Voluntary Work & $\begin{array}{l}\text { Work for organization as a volunteer, meetings, informal } \\
\text { clubs and societies, political party meetings }\end{array}$ \\
\hline Computer Use & $\begin{array}{l}\text { Computing, programming, seeking information by means of } \\
\text { computer or another data medium, sending emails, electronic } \\
\text { communication etc. }\end{array}$ \\
\hline Recreational Study & $\begin{array}{l}\text { Attending classes and lectures, borrowing books, visiting the } \\
\text { library, reading in the library }\end{array}$ \\
\hline
\end{tabular}

\section{T A B L E 1. Contents of Third Age/Active Leisure Index}

Overall, the strength of this 7-item index is that it includes a wide range of leisure activities and is thus not restrictive in terms of cultural taste, which is often the case for analyses of active leisure using data from conventional social surveys that solely cover forms of highbrow leisure relevant to specific social class groups. Rather, our index corresponds to a broader notion of cultural and leisure participation and in this respect non-participation in

$1 \quad$ However, it should be noted that an analysis using an active leisure index that included only the 6 out-ofhome leisure pursuits and excluded computer use was also conducted produced very similar results to the ones reported in this article. 
any of the activities of the index during a regular week can be taken as a symptom of an exclusively 'passive' leisure lifestyle. On the other hand, participation can be understood as an indicator of a more engaged and active older person, i.e. a third ager.

We employ 2 different operational definitions of a third ager according to participation: First, a 'liberal' definition of a third ager as a person with a score of 1 ore more on the Third Age index, which is a retiree who reported participating in one of the index activities at least once across the two surveyed days. Our index does not make use of information regarding activities' duration and only participation is used for classifying a person as a third ager. It is therefore possible that some people that engage solely in one activity for a relatively short time period during the two days are classified as third agers according to the 'liberal' definition, while in reality they primarily lead a more passive lifestyle. It was thus decided to also use a more 'strict' definition of a third ager as a person with a score of 2 or more on the index, i.e. a retiree who participated in at least two active leisure activities during the two diary days. This allows the calculation of the proportions of third agers whose post-retirement life is characterized by a more consistent active leisure engagement.

\section{3) Independent Variables}

We assess the relationship of a Third Age leisure lifestyle with a series of socio-demographic characteristics. Gender, age, health status, social class and level of educational attainment are the variables examined in our bivariate analyses and multivariate statistical models.

The health status variable is derived from respondents' answer to the question: 'do you have any long-term illness, health problem or disability which limits your daily activities or the work you can do?' This question constitutes a global health measure and has been shown to be an accurate indicator of objective health status (Manor et al. 2001).

Level of educational attainment was measured with the question 'what is the highest qualification you have gained'. Responses were grouped into 10 categories, which are collapsed into 3 categories: 1) high level (degree level education, nursing qualification, HNC and A-levels vocational level three), 2) low/trade level (O-levels, GCSE, trade apprenticeships, other vocational and professional qualifications, and city guilds), and 3) no qualifications.

Social class is measured by the three-category National Statistics Socio-Economic 
Classification, (NS-SEC) which classifies respondents according to the employment relations and occupational conditions of their last job. As well as managerial/higher professional, intermediate, and routine/manual social class groups, a fourth group consists of people that have either never worked or were not assigned to an occupational class during the interview. Social class is understood as a proxy for an individual's command of financial resources, that cannot be analysed directly due to missing data.

We also examined the influence of marital status and living arrangements. However, no statistically significant associations were found with the outcome variable(s) and these variables are not presented in the results section. Ethnicity was not related to a Third Age lifestyle either, but this might be due to the small numbers of older people from non-English ethnic groups in our analytic sample.

\section{4) Analytical Technique}

The dependent dichotomous variable of interest is a third ager with a binary response (yes/no). To model the probability of a person being a third ager, we use additive logistic regression models. Two logistic regression models are presented for each of the 2 definitions of a third ager discussed previously: an initial model adjusted by sex and age, and a fullyadjusted final model. Specifying these two different models enables a better assessment of the robustness of our findings and the influence of socio-demographic characteristics for the formation of Third Age lifestyles of varying degrees.

\section{RESULTS}

\section{1) Socio-demographic profile of the analytic sample}

What is characteristic for this group of retirees is that a large proportion of both men and women have no educational qualifications, namely $63 \%$ of men and $74 \%$ of women. Men are more educated, with $21 \%$ reporting high qualifications as opposed to only $12 \%$ of women (see Table 2). The same pattern of sex difference is found in social class groupings: $31 \%$ of older men have a professional/managerial occupational background as opposed to $15 \%$ of women. Women primarily had intermediate or routine manual occupations (20 and 43\% respectively) while $22 \%$ in this sample never had a paid job, which is a result of the impact marriage and motherhood had on the employment trajectories of women of older cohorts in Britain (Dex 1984). 
There are no significant gender differences in health status, with $39 \%$ of men and $42 \%$ of women reporting a long-standing limiting illness. In contrast, a key difference between men and women regards marital status: $74 \%$ of men are married and only $18 \%$ are widowed, while the proportions are very different for women: $45 \%$ are married and $45 \%$ are widowed.

\section{T A B L E 2. Socio-demographic profile}

\begin{tabular}{|c|c|c|}
\hline & Men & Women \\
\hline & $\%$ & $\%$ \\
\hline \multicolumn{3}{|l|}{ Education } \\
\hline High & 21.5 & 12.2 \\
\hline Low/Trade & 15.4 & 13.3 \\
\hline No qualification & 63.1 & 74.4 \\
\hline \multicolumn{3}{|l|}{ Social Class } \\
\hline Managerial and Professional & 31.4 & 14.9 \\
\hline Intermediate & 13.1 & 20.9 \\
\hline Routine and Manual & 39.8 & 42.6 \\
\hline Never worked/Missing & 15.6 & 21.7 \\
\hline \multicolumn{3}{|l|}{ Age Group } \\
\hline $65-69$ & 33.6 & 29.5 \\
\hline $70-74$ & 27.6 & 26.2 \\
\hline $75-79$ & 22.5 & 24.3 \\
\hline $80-84$ & 10.8 & 12.7 \\
\hline $85-98$ & 5.5 & 7.3 \\
\hline \multicolumn{3}{|l|}{ Marital Status } \\
\hline Married & 74.3 & 44.6 \\
\hline Never Married & 3.8 & 5.3 \\
\hline Divorced/Separated & 4.5 & 5.4 \\
\hline Widowed & 17.5 & 44.8 \\
\hline \multicolumn{3}{|l|}{ Limiting Illness } \\
\hline No illness & 36.8 & 35.8 \\
\hline Illness but not limiting & 24.7 & 22.6 \\
\hline Limiting Illness & 38.5 & 41.6 \\
\hline $\bar{n}$ & 616 & 919 \\
\hline
\end{tabular}

Note: 1. Source: UK 2000 Time Use Survey 2. $\mathrm{n}=1615$; weighted

\section{2) Time-Use Patterns of British People over 64 years}

This section provides information on the time use patterns and active leisure participation of British older people. Table 3 shows the average time spent on different types of activities for the sample by gender. The active leisure category consists of the activity codes presented in Table 1 while the passive leisure category consists of indoor activities such as mass media consumption (watching television, listening to the radio) as well as other time periods spent at home where diarists reported resting or not doing anything specific (e.g. doing nothing, 
waiting for time to pass).

\section{T A B L E 3. Mean Time Spent on Different Activities over the 2 diary days}

\begin{tabular}{lll}
\hline ACTIVITIES & Men & Women \\
\hline Personal Care & $11 \mathrm{hrs} 26 \mathrm{~min}$ & $11 \mathrm{hrs} \mathrm{25min}$ \\
Domestic work & $3 \mathrm{hrs} 7 \mathrm{~min}$ & $3 \mathrm{hrs} \mathrm{49min}$ \\
Social Activities & $1 \mathrm{hr} 22 \mathrm{~min}$ & $1 \mathrm{hr} 32 \mathrm{~min}$ \\
Caring for others & $13 \mathrm{~min}$ & $13 \mathrm{~min}$ \\
Active Leisure & $27 \mathrm{~min}$ & $17 \mathrm{~min}$ \\
Passive Leisure & $5 \mathrm{hrs} 33 \mathrm{~min}$ & $5 \mathrm{hrs} 2 \mathrm{~min}$ \\
Other & $1 \mathrm{hr} 52 \mathrm{~min}$ & $1 \mathrm{hr} 42 \mathrm{~min}$ \\
\hline Total & $\mathbf{2 4 h r s}$ & $\mathbf{2 4 h r s}$ \\
\hline Notes: 1. Source: UK 2000 Time Use Survey; $\mathrm{n}=1615 ;$ weighted \\
\multicolumn{1}{r}{ 2. Estimates are derived solely from activities recorded as primary from respondents }
\end{tabular}

Both men and women spend the same amount of time on caring activities for other members of the household ${ }^{2}$ and on personal care. However, women spend more time doing household tasks (a gender difference of 42 minutes) while men spend more of their time on leisure activities. Women on average also spend a somewhat longer period of time on social activities (i.e. talking on the phone, receiving visitors etc.) than men. Passive forms of leisure constitute a dominant type of activity for both sexes (watching television is the second most frequently reported activity in older people's diaries after sleeping), while very few minutes are spent on average on active leisure activities (27 minutes for men and 17 minutes for women).

It should be noted that these estimates refer to the entire sample and therefore the calculation of average time spent on active leisure takes into account a great deal of zeroes (i.e. 0 minutes) from retirees with no active leisure engagement on the two surveyed days. Table 4 shows the participation rates and average time participants spent on each of the seven active leisure activities of the index.

Participation rates in Third Age activities are low for both sexes across the two diary days (Table 4a). Among men the highest participation rates are found for physical exercise $(12 \%)$, use of computers (8\%), voluntary work (8\%) and outdoor entertainment activities (8\%).

2 Further analyses did not show significant social class differences in caring responsibilities for other adults in the household and/or for (grand)children. 
Overall, women have lower participation rates in all seven activities. With the exception of the use of computers where women have very low participation (2\%), there is the same rank order of activities as in the case of men. Table $4 \mathrm{a}$ shows that, when focusing solely on participants, there are generally high Third Age activity durations, which essentially means that retirees who engage in active leisure pursuits do so in an organized way and that this engagement forms an important part of their lifestyle.

\section{$T A B L E$ 4. Active leisure participation rates and mean time spent on each activity over 2 days by participants only}

\begin{tabular}{lllll} 
Activities & Men (n=696) & \multicolumn{2}{l}{ Women (n=919) } \\
\hline (a) Type of Activity & $\begin{array}{l}\text { \% of sample } \\
\text { (count) }\end{array}$ & Mean time & $\begin{array}{l}\text { \% of sample } \\
\text { (count) }\end{array}$ & Mean time \\
\hline Arts & $4.8(34)$ & $1 \mathrm{hr} 3 \mathrm{~min}$ & $3.5(32)$ & $45 \mathrm{~min}$ \\
Entertainment & $8.3(58)$ & $1 \mathrm{hr} 17 \mathrm{~min}$ & $5.4(50)$ & $1 \mathrm{hr} 21 \mathrm{~min}$ \\
Hobbies in Nature & $0.7(5)$ & $56 \mathrm{~min}$ & $0.4(4)$ & $14 \mathrm{~min}$ \\
Physical Exercise & $12.2(85)$ & $1 \mathrm{hr} 14 \mathrm{~min}$ & $8.0(73)$ & $53 \mathrm{~min}$ \\
Voluntary Work & $8.3(58)$ & $1 \mathrm{hr} 8 \mathrm{~min}$ & $6.9(70)$ & $1 \mathrm{hr} 22 \mathrm{~min}$ \\
Use of computers & $8.2(57)$ & $11 \mathrm{~min}$ & $2.3(22)$ & $10 \mathrm{~min}$ \\
Recreational Study & $3.7(26)$ & $39 \mathrm{~min}$ & $4.4(40)$ & $38 \mathrm{~min}$ \\
\hline (b) Number of activities & Men (n=696) & & Women (n=919) \\
\hline 0 & $63.4(441)$ & & $72.5(667)$ & \\
1 & $25.7(179)$ & & $22.1(202)$ & \\
2 & $10.9(76)$ & & $5.4(50)$ & \\
\hline
\end{tabular}

Note: 1. Source: UK 2000 Time Use Survey; weighted

Table $4 \mathrm{~b}$ confirms that the vast majority of retirees (63.4\% of men and 72.5 of women) do not engage in any of the 7 activities associated with the concept of Third Age leisure during a typical week. Approximately a quarter of the population engages in only one such activity, while the proportions of those that engage in more than one activity are noticeably low, at $10 \%$ for men and 5\% for women. These figures justify our analytical approach that examines participation in one or two Third Age activities, as the latter represents the higher degree of weekly active leisure engagement for older people in our sample. Overall, Table 4 demonstrates that, across a representative weekend day and a weekday, Third Age activities are practised only by a small minority of retirees, and that more men than women engage in such pursuits on a regular basis. This indicates that the 'new leisured experience of ageing' as described by Third Age literature has only eventuated for a relatively small minority of retirees. The next section explores the socio-economic characteristics of third agers.

\section{3) Socio-economic correlates of a Third Age Lifestyle: Bivariate Analyses}


Table 5 shows the proportions of third agers for both operational definitions, providing information on their socio-demographic profile. A strong association between passive leisure lifestyles and chronic illness is found: Among men reporting a limiting illness, 29\% are third agers according to the 'liberal' definition (i.e. engaging in a least one 'active' leisure pursuit during a typical week) and $6 \%$ according to the 'strict' definition (i.e. engaging in 2 or more 'active' leisure pursuits during a typical week), while the percentages of third agers are considerably higher in other health status groups. The same pattern is found for women although differences between groups are not as pronounced. Level of educational attainment influences engagement with Third Age leisure pursuits. The pattern appears to be linear and particularly pronounced for both operational definitions, with more men and women of high educational background being third agers compared to those with lower levels of educational attainment.

Patterns are not as clear in the case of social class, except that retirees with routine and manual occupational backgrounds consistently lead more passive lifestyles than other social class groups. This holds for both sexes and for both definitions of third agers. However, the proportions of third agers from higher professional and intermediate backgrounds are almost the same. It is also important to note that there are more third agers in the 'Never worked/missing' group than in the lower social class, which may be an indicator of relatively higher financial resources of this category. Finally, results also underline an age gradient for both sexes for the liberal definition. A similar age gradient is found for very active women (i.e. women engaging in at least 2 'active' leisure pursuits during a typical week), but not for very active men. The remainder of this section presents results from multivariate logistic regression models that aim to disentangle these effects, and assess their relative contribution for the realization of a Third Age post-retirement lifestyle. 


\section{$T A B L E$ 5. Percentages of third agers in different socio-economic groups}

\begin{tabular}{lllll}
\hline & \multicolumn{2}{l}{ Liberal Definition } & \multicolumn{2}{l}{ Strict Definition } \\
& Men & Women & Men & Women \\
\hline & $\mathbf{3 6 . 5}$ & $\mathbf{2 7 . 5}$ & $\mathbf{1 0 . 2}$ & $\mathbf{5 . 4}$ \\
\hline Variable & & & & \\
\hline Education & & & & \\
High & 57.7 & 50.9 & 20.1 & 19.6 \\
Low/Trade & 37.4 & 35.0 & 9.3 & 8.9 \\
No qualification & 29.2 & 22.4 & 8.2 & 2.6 \\
Social Class & & & & \\
Managerial and Professional & 48.6 & 38.8 & 15.0 & 13.4 \\
Intermediate & 41.6 & 35.1 & 16.9 & 8.0 \\
Routine and Manual & 23.6 & 19.5 & 5.9 & 2.1 \\
Never worked/Missing & 41.1 & 28.6 & 10.4 & 4.6 \\
Age Group & & & & \\
65-69 & 42.7 & 34.3 & 12.0 & 7.7 \\
70-74 & 37.0 & 25.7 & 8.3 & 5.8 \\
75-79 & 31.4 & 26.9 & 9.3 & 4.0 \\
80-84 & 30.3 & 24.1 & 10.3 & 4.3 \\
85-98 & 31.6 & 13.4 & 11.3 & 3.0 \\
Limiting Illness & & & & \\
No illness & 39.4 & 32.4 & 15.4 & 8.0 \\
Illness but not limiting & 48.5 & 34.3 & 13.3 & 6.0 \\
Limiting Illness & 28.8 & 20.4 & 5.8 & 3.3 \\
\hline Note: 1 Source: UK 2000 Tim & & & & \\
\end{tabular}

Note: 1. Source: UK 2000 Time Use Survey; n=1615; weighted

\section{4) Socio-economic correlates of a Third Age Lifestyle: Bivariate Analyses}

Two logistic regression models are specified to examine the effects of socio-demographic characteristics on the probability of an older person being a third ager. For each predictor variable, the category with the lowest probability for an active leisure lifestyle in bivariate analyses is defined as the reference category. Table 6 shows the age-sex adjusted as well as the fully adjusted models for both outcome variables.

Model 1 includes sex and age. In both the 'liberal' and the 'strict' models, men present higher odds of being third agers than women $(\mathrm{OR}=1.52 \mathrm{p}<0.001$ and $\mathrm{OR}=2.01, \mathrm{p}<0.001$ respectively). In the 'liberal' Model 1, age is a very significant predictor of an active leisure lifestyle, with people between 65-69 years are significantly more likely to be third agers than the reference category of people over the age of 85 years $(\mathrm{OR}=2.21, \mathrm{p}<0.001)$. However, age is 
not a significant predictor of a consistent engagement with a Third Age lifestyle (strict definition).

T A B L E 6. Logistic Regression Models predicting Third Agers

\begin{tabular}{|c|c|c|c|c|}
\hline \multirow[b]{2}{*}{ Variable } & \multicolumn{2}{|c|}{ Liberal Definition } & \multicolumn{2}{|c|}{ Strict Definition } \\
\hline & Model 1 & Final Model & Model 1 & Final Model \\
\hline$\overline{\operatorname{Sex}}$ & $* * *$ & $* *$ & $* * *$ & *** \\
\hline Male & $1.52 * * *$ & $1.38 * *$ & $2.01 * * *$ & $1.76 * * *$ \\
\hline Female & 1 & 1 & 1 & 1 \\
\hline Age & $* * *$ & NS & NS & NS \\
\hline $65-69$ & $2.21 * * *$ & 1.91 & 2.65 & 2.08 \\
\hline $70-74$ & 1.67 & 1.57 & 1.92 & 1.7 \\
\hline $75-79$ & 1.57 & 1.58 & 2.25 & 2.34 \\
\hline $80-84$ & 1.50 & 1.47 & 2.45 & 2.37 \\
\hline $85-98$ & 1 & 1 & 1 & 1 \\
\hline Limiting Illness & & $* * *$ & & $* * *$ \\
\hline No illness & & $1.56 * * *$ & & $2.75 * *$ \\
\hline Illness but not limiting & & $1.91 * * *$ & & 2.04 \\
\hline Limiting & & 1 & & 1 \\
\hline Social Class & & $* * *$ & & $*$ \\
\hline Managerial and Professional & & $1.94 * * *$ & & $2.17 *$ \\
\hline Intermediate & & $2.10 * * *$ & & $2.80 * *$ \\
\hline Routine and Manual & & 1 & & 1 \\
\hline Never worked/Missing & & $1.83 * * *$ & & 1.71 \\
\hline Education & & $* * *$ & & $* * *$ \\
\hline High & & $2.42 * * *$ & & $3.31 * * *$ \\
\hline Low/Trade & & $1.41 *$ & & 1.68 \\
\hline No qualifications & & 1 & & 1 \\
\hline Nagelkerke R square & 0.03 & 0.13 & 0.03 & 0.15 \\
\hline
\end{tabular}

Note: 1. Source: UK 2000 Time Use Survey; $\mathrm{n}=1615$; weighted 2. Significance of difference from

reference category $* \mathrm{p}<0.05, * * \mathrm{p}<0.01 . * * * \mathrm{p}<0.001$

The sequential inclusion of the variables of health status, social class and level of educational attainment significantly improved both logistic models as indicated by the significance of differences in the log-likelihood ratios for each block (not reported in the Table), and the increase in the pseudo R-square. Table 6 displays only the fully-adjusted regression models. After controlling for health, social class and educational attainment, the effect of gender is slightly reduced in both models, demonstrating that gender differences in active leisure participation are partly a result of gender inequalities in economic resources and human capital. The magnitude of the age effect is also reduced in the 'liberal' model, and the variable becomes insignificant.

Health status has a very strong effect in both models, with those that do not suffer from 
any longstanding illness more likely to have an active lifestyle after retirement than those with a longstanding limiting illness $(\mathrm{OR}=1.56, \mathrm{p}<0.01)$. The effect is greater in the case of the 'strict' definition, with the healthiest group of older people presenting an odds ratio of 2.75 $(\mathrm{p}<0.01)$ in the fully adjusted model.

Educational attainment and social class are significant predictors of participation in active leisure pursuits. Educational level is a very significant predictor for both operational definitions with highly educated people having much higher odds of being third agers $(\mathrm{OR}=2.42, \mathrm{p}<0.001, \mathrm{OR}=3.31, \mathrm{p}<0.001$ for the liberal and the strict definition respectively) compared to older people with no educational qualifications.

Social class remained very significant in the 'liberal' model but only marginally significant after controlling for education in the 'strict' model. All social class categories have a higher probability of engaging in Third Age leisure than the working class (i.e. routine and manual) group. However, the pattern is not linear and retirees from an intermediate occupational background have a higher probability of being third agers than those who have worked in managerial and higher professional occupations. The 'never worked/missing' group is also more likely to have an active leisure lifestyle than the routine and manual social class group (OR=1.83, p <0.001, strict model), which was previously shown in bivariate examinations.

Overall, the specified logistic models demonstrate the strong influence of sociodemographic factors on weekly participation in active leisure pursuits. Our findings do not support theoretical propositions regarding the irrelevance of socio-demographic characteristics in lifestyle determination in later life. Rather, results suggest a strong influence of health status and of previous life-course stages and socio-economic positions on daily life and leisure participation after the relinquishment of work roles.

\section{5) Results from analysis replication with 2005 time-use data}

We also replicated the analysis with the smaller scale 2005 follow-up time use survey ( $n=4989$ ), which constituted a separate module of the Omnibus 2005 Survey (for more information see ONS 2006). The multivariate logistic models produced very similar results in terms of the determinants of Third Age lifestyles, providing confidence for the persisting significance of health and economic inequalities in influencing leisure participation in older 
ages in Britain. Participation rates were also very similar for the majority of Third Age activities with the sole exception of computer/internet use, which had increased significantly amongst older people. However, as previously discussed in the methodology section, participation in an activity indicates different lifestyles and carries distinctive meanings at different periods of time and it is thus debatable whether internet use should still be classified as active leisure nowadays or whether it has become more similar to passive media consumption, such as watching television.

\section{DISCUSSION AND CONCLUDING REMARKS}

In this article we operationalised the theoretical idea of the Third Age as participation in active leisure pursuits and estimated the proportions of third agers amongst British older people based on data from the 2000 UK Time Use Survey. We then examined the relative effects of socio-economic circumstances on the probability of a person over the age of 64 being a third ager in order to test theoretical propositions regarding the irrelevance of social divisions in the formation of post-retirement active leisure lifestyles.

Findings highlight that only a small minority of British retirees consistently engage in active leisure pursuits on a typical week. Instead, it is shown that older British people mostly participate in indoor leisure activities that could be characterized as 'low demand', such as watching television and other forms of passive mass media consumption. The active and selffulfilling 'ideal' time period following retirement described by Laslett (1989) is more likely to eventuate for healthy men of a privileged educational and occupational background. Our logistic models showed strong effects of health and socio-economic factors on active leisure participation, with both social class and level of educational attainment being strong predictors of a Third Age lifestyle. Previous studies have also corroborated the importance of socio-economic circumstances in determining participation in cultural and other active leisure pursuits in later life (Baltes and Carstensen, 1996; Gordon et al., 1976; Kolland, 1996). The stronger effects found for education for the 'strict' model that predicts a somewhat more consistent Third Age leisure lifestyle lend further support to findings reporting a strong positive correlation between availability of resources and specialization and diversity of leisure pursuits in later life (Baltes \& Carstensen 1996).

Although we also found lowered rates of participation in active leisure pursuits with increasing age (Gordon et al. 1976; Havighurst 1961), age is an insignificant variable in our 
'strict' model. Our results on age are in accordance with previous findings of age per se being less of an influence in determining participation in active and cultural activities than health and other structural factors (Kolland 1996). However, our cross-sectional dataset did not allow a full examination of the influence of cohort, age and period on active leisure participation and in this respect more research is needed to reach a conclusion regarding the different effects age may have on leisure participation in later life (e.g. generational effects on leisure preferences and habits).

Alongside level of educational attainment, health is the strongest predictor of a Third Age lifestyle, underlining the primary effect of chronic illness on the probability of frequent participation in active leisure pursuits. This accords with previous findings reporting a dramatic fall of participation by health status and a strong association between 'low demand' leisure activities and low physical health scores (Everard et al. 2000; Henderson and Dialeschki 1991).

A consistent gender difference was also found, with men more likely than women to engage in Third Age activities, even after adjusting for gender inequalities in socio-economic circumstances and health variations. Older men have a more outdoor active leisure orientation, whilst British older women continue to spend more time than men in housework activities. These findings render support to previous remarks regarding the different hindrances to leisure pursuits in later life for the two sexes (Coleman and Iso-Ahola 1993; Calasanti 1996), and provide additional evidence regarding the important influence of previous life-course experiences and gendered roles in active leisure participation in later life. Calasanti (1996) has noted that retirement signifies a freedom of choice of leisure activities for men while for women it signifies a free choice to select different days and times to do domestic work. Indeed, our data suggest that men may be potentially benefiting from their relative freedom in pursuing an active leisure lifestyle during working life and may thus possess a leisure advantage after retirement over women, whose unequal share and quality of free time due to increased domestic responsibilities and motherhood roles in previous lifecourse stages (Bittman and Wajcman 2000; Deem 1996) may continue to compromise their leisure participation in later life.

Another possible reason for this gender difference is that the activities included in our Third Age index are mostly of a masculine orientation, which relates to previously noted critiques regarding the normative male-centered middle class bias of the concept of the Third 
Age (Bury 1995; Wahl, Tesch-Römer and Hoff 2007; Wray 2007). As mentioned earlier, inequalities experienced during previous life-course stages may foster different understanding of successful ageing and quality of life in later life (Wray 2003). In this respect it may be reasonable to claim that there exist other activities and uses of free time such as grandparenthood or involvement in informal social networks ${ }^{3}$ that may be indicative of a different type of successful ageing that does not coincide with the current dominant Western centric theories of ageing (Wray 2007). Future analyses of time-use surveys could chart different late life lifestyles and their association with socio-economic disadvantage and cultural values of different social groups.

Overall, this study indicates that systems of gender and class inequality and disadvantage continue to operate after retirement, and that the cultivation of an active leisure lifestyle is inextricably intertwined with an older persons' social characteristics and previous life-course experiences. This lends support to claims of political economists' of ageing that the risks associated with ageing significantly differ between social groups and 'that this core message is as true today as it was nearly thirty years ago' (Walker 2006: 69), contrary to postmodernist claims that overemphasize human agency.

\section{ACKNOWLEDGEMENTS}

This research was based on the United Kingdom Time Use Survey 2000, produced by the Office for National Statistics and IPSOS-RSL and supplied by the UK Data Archive, which bear no responsibility for any analysis and interpretation in this article. The data are Crown Copyright. The authors acknowledge funding from the European Union Marie Curie Research Training Network ‘The Biomedical and Sociological Effects of Sleep Restriction' (MCRTN-CT2004-512362) and from the Fund for Women Graduates, and also thank the two anonymous reviewers and the editors of Sociological Research Online for their constructive comments and suggestions for improving this article.

\section{REFERENCES}

ABRAHAM, K.G., MAITLAND, A. and BIANCHI, S.M. (2006) 'Nonresponse in the American Time Use Survey: Who is Missing from the Data and How Much Does it Matter?', Public Opinion Quarterly, vol. 70, no. 5, pp. 676-703.

3 Indeed women spend on average 10 more minutes per day in 'social activities' than men (Table 3). 
ARBER, S. and EVANDROU, M., (eds), (1993), Ageing, Independence and the Life Course. London: Jessica Kingsley Publishers

ARBER, S. and GINN, J., (eds), (1995), Connecting Gender and Ageing: A Sociological Approach. Buckingham: Open University Press.

BALTES, M.M. and CARSTENSEN, L.L. (1996) 'The Process of Successful Ageing', Ageing and Society, vol. 16, no. 4, pp. 397-422.

BASS, S. A., and CARO, F. G. (2002) Productive Aging: A Conceptual Framework. In N.

Morrow-Howell, J. E. Hinterlong, and M. W. Herraden (eds.) Productive Aging: Concepts,

Cautions, and Challenges. Baltimore, Md.: Johns Hopkins University Press.

BERNARD, K. and MEADE (1993) Women Come of Age: Perspectives in the Lives of Older Women. London: Edward Arnold.

BITTMAN, M. and WAJCMAN, J. (2000). 'The Rush Hour: The Character of Leisure Time and Gender Equity.' Social Forces 79(1): 165-189.

BURY, M. (1995) Ageing, Gender and Sociological Theory. In Arber, S. \& Ginn, J. (eds.)

Connecting Gender and Ageing. A Sociological Approach. Buckingham: Open University Press.

BULTENA, G and WOOD, V. (1970) Leisure Orientation and Recreational Activities of Retirement Community Residents, Journal of Leisure Research, vol. 2, pp. 3-15

CALASANTI, T.M. (1996) 'Incorporating Diversity: Meaning, Levels of Research, and Implications for Theory', The Gerontologist, vol. 36, no. 2, pp. 147-156.

CARR, D. and KOMP, K. (2011) 'Gerontology in the Era of the Third Age: Implications and Next Steps'. New York: Springer

CHUNG, S., DOMION, M. STEARNS, S. and POPKIN, B. (2009) 'Retirement and Physical Activity Analyses by Occupation and Wealth', American Journal of Preventive Medicine, vol. 36 , no. 5, pp. $422-428$

COLEMAN, D. and ISO-AHOLA, S.E. (1993) 'Leisure and Health: The Role of Social Support and Self-Determination', Journal of Leisure Research, vol. 25, no. 2, pp. 111-128.

CUMMING, E. and HENRY, W.E. (1966) Growing Old: The Process of Disengagement, New York: Basic Books.

DANNEFER, D. (2003) 'Cumulative Advantage/Disadvantage and the Life-Course: CrossFertilizing Age and Social Science Theory' Journals of Gerontology Series B-Psychological Sciences, vol. 58, no. 6, S327-S337

DEEM, R (1982) 'Women, Leisure and Inequality' , vol. 1., no. 1, pp. 29-46

DEPARTMENT OF WORK AND PENSIONS (2003) 'Opportunity Age-Opportunity and Security Throughout Life' <http://www.dwp.gov.uk/policy/ageing-society/strategy-and publications/opportunity-age-first-report/> :

DEX, S. 1984. Women's Work Histories An Analysis of the Women and Employment Survey. London: Department of Employment.

EVERARD, K.M., LACH, H.W., FISHER, E.B. and Baum, M.C. (2000) 'Relationship of Activity and Social Support to the Functional Health of Older Adults', Journals of Gerontology

Series B: Psychological Sciences and Social Sciences, vol. 55, no. 4, pp. 208-212.

FEATHERSTONE, M. and HEPWORTH, M. (1989) Ageing and Old Age: Reflections on the Postmodern Life Course. In Bytheway, B., T. Keil, P. Allatt and A. Bryman (eds.) Becoming and Being Old: Sociological Approaches to Later Life, London: Sage Publications.

GAUTHIER, A.H. and SMEEDING, T.M. (2003) "Time Use at Older Ages: Cross-national Differences', Research on Aging, vol. 25, no. 3, pp. 247-274.

GAUTHIER, A.H. and SMEEDING, T.M. (2001) Historical Trends in the Patterns of Time Use of Older Adults. Organization for Economic Cooperation and Development, Aging Working Paper

GILLEARD, C. (1996) 'Consumption and Identity in Later Life: Toward a Cultural

Gerontology', Ageing and Society, vol. 16, no. 4, pp. 489-498.

GILLEARD, C. and HIGGS, P. (2005) Contexts of Ageing: Class, Cohort and Community. 
Cambridge: Polity Press.

GILLEARD, C., HIGGS, P., HYDE, M., WIGGINS, R. and BLANE, D. (2005). 'Class, Cohort, and Consumption: The British Experience of The Third Age', Journal of Gerontology: Social Sciences, vol. 60B, no. 6, pp. 305-310.

GILLEARD, C.J. and HIGGS, P. (2000) Cultures of Ageing: Self, Citizen and the Body.

Harlow: Prentice Hall.

GORDON, C., GAITZ, C.M. And SCOTT, J. (1976) 'Leisure and Lives: Personal Expressivity across the Life Span', Handbook of Aging and the Social Sciences, pp. 310-341.

HAVIGHURST, R.J. (1961) The Nature and Values of Meaningful Free-time Activity. In Kleemeier, R.W. (ed.) Aging and Leisure. New York: Oxford University Press.

HENDERSON, K.A. and DIALESCHKI, M.D. (1991) 'A Sense of Entitlement to Leisure as Constraint and Empowerment for Women', Leisure Sciences, vol 13, no. 1, pp. 51-65.

HOOKER, K. and VENTIS, D.G. (1984) 'Work Ethic, Daily Activities, and Retirement

Satisfaction', The Journal of Gerontology, vol. 39, no. 4, pp 478-484.

HOWE, C.Z. (1987) Selected Social Gerontology Theories and Older Adult Leisure

Involvement: A Review of the Literature, Journal of Applied Gerontology vol. 6, no. 4, pp. 448463

JAMES, J. B. and WINK, P.W. (2007) The Crown of Life: Dynamics of the Early

Post-retirement Period. In James, J. B., P.W. Wink and K.W., Schaie (eds.) Annual Review of Gerontology and Geriatrics, Vol 26. New York: Springer Publishing.

KALFS, N. (1993) Hour by Hour: Effects of the Data Collection Mode in Time Use Research, Amsterdam: NIMMO

KLEEMEIER, R.W. (1961) Aging and Leisure. New York: Oxford University Press.

KOLLAND, F. (1996) Kulturstile im Alter [Cultural Styles in later life]. Wien: Bohlau.

LARSON, R., ZUZANEK, J. and MANNELL, R. (1985) 'Being Alone Versus Being With

People: Disengagement in the Daily Experience of Older Adults', The Journal of Gerontology, vol. 40, no. 3, pp. 375-381.

LASLETT, P. (1987) 'The Emergence of the Third Age', Ageing and Society, vol. 7, no. 2, pp. $133-160$.

MANOR, O., MATTHEWS, S. and POWER, C. (2001) 'Self-rated Health and Limiting

Longstanding Illness: Inter-relationships with Morbidity in Early Adulthood', International Journal of Epidemiology, vol. 30, pp. 600-607.

MATTHEWS, R.J. JAGGER, C. and HANCOCK, R.M. (2005) 'Does Socio-economic Disadvantage Lean to a Longer, Healthier Old Age?' Social Science and Medicine, vol. 62, no 10, pp. 2489-2499

MICHELSON, W., (2005) Time Use: Expanding the Explanatory Power of the Social Sciences. London: Paradigm Publishers

NEUGARTEN, B. (1974) 'Age Groups in American Society and the Rise of the Young-old', The Annals of the American Academy of Political and Social Science, Vol. 415, no. 1, pp. 187-198.

ONS (2006) The Time Use Survey 2005: How we Spend our Time.

http://www.statistics.gov.uk/articles/nojournal./time_use_2005.pdf

ONS (2003) The United Kingdom 2000 Time Use Survey Technical Report

http://www.statistics.gov.uk/downloads/theme social/UKTUS TechReport.pdf

PATTERSON, I. (1996) 'Participation in Leisure Activities by Older Adults After a Stressful

Life Event: The Loss of a Spouse', vol. 42, no. 2, 123-142

PHILIPSON, C. (1998) Reconstructing Old Age: New Agendas in Social Theory and Practice.

London: Sage Publications

RIDDICK, C. C. (1986) 'Leisure Satisfaction Precursors', Journal of Leisure research, vol. 18, pp. 259-65.

ROBINSON, J/P and GODBEY, G. (1999) Time for Life: The Surprising Ways Americans Use Their Time. University Park, PA: Pennsylvania State University Press.

SEALS, S.D., CLANTON, K., AGARWAL, R., DOSWELL, C. and THOMAS, C.M. (2008) 
'Lifelong Learning: Becoming Computer Savvy at a Later Age', Educational Gerontology, Vol. 34, no. 12 , pp. 1055-1069.

SHAPIRA, N., BARAK, A. and Gal, J. (2007) 'Promoting Older Adults Well-being through Internet Training and Use'. Aging and Mental Health, vol. 11, no. 5, pp. 477-484.

SNEEGAS, J.J. (1986) 'Components of Life Satisfaction in Middle and Later Life Adults: Perceived Social Competence, Leisure Participation and Leisure Satisfaction', Journals of Leisure Research, vol. 18, no. 4, pp. 248-256.

VAN DER PLOEG, H.P., MEROM, D., CHAY, J.Y., BITTMAN, M., TROST, S.G. and BAUMAN, A.E. (2010) 'Advances in Population Surveillance for Physical Activity and Sedentary Behavior: Reliability and Validity of Time Use Surveys', American Journal of Epidemiology, vol. 172, no. 10, pp. 1199-1206.

VAN DER PLOEG, H.P.. (2000) Time-use Measurement and Research: Report of a Workshop, Washington DC: National Academy Press.

VERGHESE, J., LIPTON, R.B. KATZ, M.J. HALL, C.B., DERBY, C., KUSLANSKY, G., AMBROSE, A.F., SLIWINSKY, M. and BUSCHKE, H. (2000) 'Leisure Activities and the Risk of Dementia in the Elderly', New England Journal of Medicine, vol. 348, no. 25, pp. 2508-2516 WAHL, H.W., TESCH-ROMER, C. and HOFF, A. (eds.) 2007. New Dynamics in Old Age: Individual, Environmental, and Societal Perspectives. New York: Baywood Publishing Company Inc.

WALKER, A. (2006) Re-examining the Political Economy of Ageing: Understanding the Structure/Agency Tension. In Baars, J., D. Dannefer, C. Phillipson and A.Walker (eds.) Aging, Globalization and Inequality: The New Critical Gerontology. New York: Baywood Publishing Company.

WEISS, R.S. and BASS, S.A. (eds.) (2002) Challenges of the Third Age: Meaning and Purpose in Later Life. New York: Oxford University Press

WRAY, S (2007) To What Extent do Ethnic \& Cultural Diversity Influence Women's Experiences of Growing Older? In: Age \& Gender, The Age Institute, pp. 1-13.

WRAY, S. (2003) 'Women Growing Older: Agency, Ethnicity and Culture', Sociology, vol. 37, no. $3,511-527$. 